\title{
NSW HEALTH ESTABLISHES THE CENTRE FOR PUBLIC HEALTH NUTRITION
}

\section{Jane Moxon, Edwina Macoun and Philip Vita \\ Health Promotion Branch \\ NSW Department of Health}

The establishment of the Centre for Public Health Nutrition represents a major new investment in public health nutrition by the NSW Department of Health.

The Centre for Public Health Nutrition aims to:

- build capacity to monitor the food and nutrition situation in NSW

- assist workforce development

- support best practice in public health nutrition.

\section{WHY ESTABLISH A CENTRE FOR PUBLIC HEALTH NUTRITION IN NSW?}

Improved nutrition is second only to tobacco use as the most important preventable health measure. Nutrition is a key element of chronic disease prevention as diet-related disease costs Australia at least $\$ 2.5$ billion per year in health-care costs and lost earnings.

Nutrition is a highly complex issue and is determined by individual choice, the social environment, and the food supply. If the nutritional status of NSW residents is to be improved, action is required by the health system at several levels. This includes:

- continuing to improve the research base for linking dietary factors with health outcomes;

- providing evidence-based public health nutrition programs to influence food choice;

- ensuring the quality and safety of the food supply;

- providing an adequate food supply at reasonable cost to consumers;

- ensuring access to and availability of appropriate foods, particularly to those nutritionally vulnerable groups.

Effective change in the nutritional health of populations requires a range of action including:

- the development of comprehensive programs of action that use a variety of methods and approaches;

- policy development;

- development of best practice guidelines;

- workforce development within the field of nutrition;

- updating current legislation;

- effective communication strategies and community development.

In establishing the Centre for Public Health Nutrition, NSW Health recognised the need to increase its capacity for planning, developing and monitoring public health nutrition initiatives. A systematic planning process involving the development of the State nutrition monitoring report and consultations with key stakeholders highlighted this need.

\section{THE GOAL OF THE CENTRE}

The goal of the Centre is to enable NSW Health to establish and maintain a State-level food and nutrition monitoring system that supports workers needs for information, and complements national monitoring efforts. The Centre will also assist with strategy development and quality improvement support in delivering public health nutrition programs within the NSW health system. The Centre will:

- improve access for decision-makers to quality information available about the food and nutrition situation in NSW, relevant to statewide and Area Health Service priorities;

- provide an integrated strategic approach to nutrition at State and Area health service levels that is coordinated with, and complementary to, national policies and strategies;

- support public health workforce development in NSW to improve the use of information for decision-making, policy formulation and practice relating to public health nutrition;

- identify priorities for applied research and program evaluation that will contribute to 'best practice' in community-public health nutrition.

These outcomes are expected to lead to effective, sustainable public health nutrition interventions at both local and State levels, in addition to raising the profile of public health nutrition among health service leaders in NSW.

\section{A CENTRE OF EXCELLENCE}

The Nutrition Research Foundation of the University of Sydney won the tender to establish and manage the Centre. The Centre, to be located at the University of Sydney, will be co-directed by Dr Karen Webb and Professor Ian Caterson. A team of experts with skills in nutrition epidemiology and monitoring, program planning and evaluation, and management and analysis of dietary data will staff the Centre.

The Centre will enable excellence in public health nutrition planning, strategy development and monitoring in NSW.

For more information about the NSW Centre for Public Health Nutrition contact Philip Vita, Acting Manager Sun Exposure, Nutrition and Physical Activity Policy Unit, NSW Department of Health, by telephone 93919661 , or by email on pvita@health.nsw.gov.au. 